\section{Obsessive-compulsive disorder and delusions revisited}

ANNE-MARIE O'DWYER and ISAAC MARKS
The diagnosis of obsessive-compulsive disorder (OCD) traditionally assumes that the patient at some point recognises the obsessions or compulsions as excessive or unreasonable. OCD is firmly classified within the 'neuroses'. However, patients with OCD exhibit varying degrees of insight into the validity of their beliefs. DSM-IV (American Psychiatric Association, 1994) makes some acknowledgement of this, specifying "with poor insight" for individuals who, "for most of the time" during the current episode, do not recognise that the obsessions or compulsions are excessive or unreasonable. ICD-10 (World Health Organization, 1992) does not address these issues, saying only that obsessional symptoms in the presence of schizophrenia should be regarded as part of the disorder. The attempt in DSM-IV to include the spectrum of insight into OCD goes some way towards acknowledging clinical reality. Occasionally, patients with OCD present with psychopathology more usually thought of as being 'psychotic'. To illustrate this, we will present five relevant case vignettes and suggest that such cases are best regarded as severe 'atypical' OCD with delusions.

\section{CASE PRESENTATIONS}

Case I (from Lelliott \& Marks, 1987)

$\mathrm{Z}$ suddenly developed rituals at age 17 . While watching television he looked up and saw a man's face at the glass kitchen door and heard a voice say: "Do the habits and things will go right". He came to believe in a 'power' that could bring him luck if he could retain it within his possession through ritualising. He bought an electric guitar which he felt contained the 'power' and would turn the controls ritualistically. He often saw a 'black dot' the size of a fist leave his body and enter some object around him. When experiencing the loss of the 'black dot' he felt compelled to ritualise to regain the 'power' that he believed was contained in it. At age 19 he began to believe that a workman possessed a second 'power' for evil and began a second set of rituals to ward off this evil power while striving to retain the good one. He believed absolutely in the 'power' and feared disastrous consequences for himself and his family should he fail to retain the good and repel the evil power.

Before his admission to hospital, obsessions and compulsions affected every area of his life. Before performing any action he felt compelled to imagine the letter ' $L$ ' and the phrase ' $\mathrm{X}$ away, power back' for up to 20 minutes. He felt unable to sit on chairs or walk on grass or leaves, and slept with his feet uncovered for fear of the 'power' being transferred to some object from which he might be unable to retrieve it. On leaving home he constantly retraced his steps to place his foot on a crack in the pavement or a leaf that he felt he had trodden on and so lost some of the 'power'. If he saw the black dot leave his body (about 20 times a day) he had to touch the object it had entered and superimpose the letter ' $L$ ' and the phrase ' $\mathrm{X}$ away, power back' in his mind until he saw the black dot return.

From age 18, $\mathrm{Z}$ also had recurrent depression, hopelessness and suicidal urges, with deliberate self-harm (overdoses and wrist-slashing) when he was in a depressed mood. He said he harmed himself to appease the power or as a wish to die "when everything was perfect" after a day of ritualising.

\section{Case 2}

Y developed beliefs about a 'power' at age 13. He felt that everyone had a certain 'quality' or 'goodness' which was stored in the brain as a 'power'. He believed that other people drained the power from him and replaced it with their own rubbish (faeces and urine). The exchange of power was triggered by an image in his mind of a face or object. When it happened he felt distressed, 'dirty' and 'horrible'. He could only regain the power by doing complex rituals. He imagined the person's face and that he had detached their head from their body and sucked the power from the major vessels of their neck or from their eyes. $\mathrm{He}$ then transferred the power back into himself by banging his palm on a particular spot on his forehead, and breathing out repeatedly. This made him feel relieved and 'good', but as the events recurred up to several times a minute the relief was 
short-lived. He felt 'compelled' at times to get revenge on people who stole his power by drawing with his finger on a wall a deformed and ugly representation. If he touched anything he left a 'power' trace behind and so had to touch it repeatedly to get the 'power' back. Y's belief in the experience was absolute. He knew it might seem strange to others but believed that if they experienced it, they would understand.

From age 17 he also had recurrent depression, hopelessness and suicidal urges requiring hospital admission.

\section{Case 3}

At the age of $8, \mathrm{X}$ had transient counting rituals associated with fear of harm coming to others. When she was 15 , after a relative died, she feared that harm would befall her family and friends unless she completed specific tasks. She thought a supernatural 'power' inserted unpleasant thoughts into her mind, e.g. "if you read that book a relative will die". She believed unshakeably that the power was supernatural, but could not explain it. To appease the 'power' and the thoughts, she developed complex counting rituals pervading her daily activities. She also did ritualistic hand-washing and checking. She avoided specific numbers, colours and clothes and counted from 0 to 8 on her fingers and toes throughout the day. She repeated rhymes, avoided multiple numbers she associated with death or harm, and brushed her hair hundreds of times a day. She felt unable to resist the rituals, as her belief in negative consequences was absolute. Before she was admitted to hospital, rituals took all of her time until she fell asleep.

$\mathrm{X}$ had two episodes of moderate depression at age 25 and 34, both associated with worsening of her OCD. She had never harmed herself.

\section{Case 4}

At the age of $7, \mathrm{~W}$ developed fear of harm coming to relatives. He engaged in handwashing and touching rituals to prevent this. Gradually he began to believe that 'spirits' or an outside force 'reminded' him to carry out his rituals lest harm should result. He associated the numbers 13 and 66 with harm and, if he saw them, believed they were placed by an external force to remind him to carry out his rituals. He defended his belief absolutely but said he could not be $100 \%$ sure "because one can never be sure about anything". He was unable to resist his rituals, as his belief in the negative consequences of not doing so was absolute. His rituals centred around numbers, complex counting, and avoidance of specific numbers. At age 31 he developed fear of contamination associated with many rituals of avoidance and hand-washing. Prior to admission he was homeless and had thrown away all his 'contaminated' possessions, carrying all he owned in two carrier bags.

\section{Case 5}

For 20 years $\mathrm{V}$ had had a fear of being transported into another world. At age 17 he worried that reflections in mirrors represented another world, and had complex checking rituals involving mirrors. This gradually spread to all reflective surfaces. $\mathrm{He}$ believed that turning on electrical switches, using the television remote control or hearing car engines turned on could cause him to be 'transported' and constantly checked to make sure this had not happened. He believed that if he ate while in another world, he would be forced to stay there, and so either avoided eating, or ate with complex rituals, or induced vomiting. Other rituals involved switching electrical switches on and off and wearing particular clothes. The 'other' world was tangibly the same as the real one, but 'felt' different - he felt that friends and family, although appearing the same, were 'different' and might have been replaced by 'doubles'. The symptoms gradually worsened, occupying all of his time prior to admission to hospital.

When he was 27 he suffered severe depression requiring in-patient care, and again at age 30 . He had no history of selfharm.

\section{DISCUSSION}

All five subjects had fixed, unshakeable beliefs of 'bizarre' (see below) content. In each case resistance against the compulsive urge and insight were lost. Early writers noted similarities between psychosis and OCD (Westphal, 1878; cited in Insel \& Akiskal, 1986), but later writers classified OCD subjects who had lost insight as schizophrenic (Rosen, 1957) or psychotic (Eisen \& Rasmussen, 1993). How should the cases above be classified, given the fixed and 'bizarre' nature of their beliefs, their lack of resistance and loss of insight?

\section{Fixity of beliefs}

The DSM-IV diagnosis of OCD assumes that the patient at some time recognises that the obsessions or compulsions are excessive or unreasonable. DSM-IV acknowledges that patients show varying degrees of insight into the validity of their belief, and specifies "with poor insight" for subjects who "for most of the time" do not recognise that their symptoms are excessive or unreasonable. It thus recognises that a given patient's strength of belief may fluctuate over time. Patients may logically repudiate their belief while in the safety of the therapist's office, but when in a 'dangerous' situation may be $100 \%$ convinced of the fact.

DSM-IV further suggests that where the obsession reaches "delusional proportions", 'delusional disorder' or 'psychotic disorder not otherwise specified' should be diagnosed in addition to OCD ("poor insight being reserved for those cases who fall between obsession and delusion"). There is no sharp divide between the delusional and non-delusional state. Schizophrenia is diagnosed where the ruminative delusional thoughts and bizarre behaviours are "not ego-dystonic and are not subject to reality testing". ICD-10 states that obsessive symptoms in the presence of schizophrenia should be regarded as part of the disorder.

Strength of belief in OCD was studied by Lelliott $e$ t al (Lelliott et al, 1988) in 49 'typical' OCD patients with compulsive rituals. Obsessive beliefs were assessed regarding fixity and bizarreness, resistance, and controllability. Fixity of belief was rated on three items: (a) how strongly the patient believed in the consequences of not ritualising; (b) the explanation of why others did not share their belief; and (c) how convinced they remained in the face of evidence to the contrary. On analysis, a third of the patients firmly believed that if they did not ritualise, the feared consequence would actually occur, $9 \%$ were convinced that only ignorance prevented others from sharing their belief, $11 \%$ firmly defended their belief in the face of contrary argument and evidence, and 12\% never tried to resist their urges.

Scores on the three fixity items correlated significantly. Of the correlations between fixity, bizarreness, resistance and 
controllability, only that between fixity and bizarreness was significant $(r=0.47$, $P<0.001)$. The findings support Lewis's view that recognition that the obsession is senseless is not an essential aspect of an obsession and that recognition of its absurdity is not always present (Lewis, 1935).

The fixity of belief in a third of the subjects in the study by Lelliott et al (1988) meant that they all met the criteria for 'psychosis' and delusional disorder in DSM-IV. To us this appears inappropriate, given that the subjects were otherwise indistinguishable from other OCD subjects in the study and responded similarly to treatment by exposure and ritual prevention.

\section{Bizarreness of content}

The five OCD patients discussed above had particularly bizarre content of thoughts and associated behaviours. DSM-IV defines delusions as "bizarre" when they are clearly implausible, are not understandable, and do not derive from ordinary life experiences (an example is a belief that a stranger has removed one's internal organs and replaced them with someone else's without leaving any scars; a less bizarre delusion is that one is under surveillance by the police). We believe that the above subjects' symptoms were bizarre in that they are not readily understandable and do not derive from common life experiences usually described by OCD subjects, such as a belief that they may develop AIDS or that harm may come to their family. The bizarre content is indistinguishable from that of other psychotic processes. In fact, DSM-IV includes bizarreness of delusional content as a diagnostic criterion for schizophrenia, and allows a diagnosis of schizophrenia based on the presence of a "bizarre" delusion. Clinicians may intuitively empathise with this concept, but DSM-IV was recently criticised for including "bizarreness" in the definition of delusions (Maj, 1998). The content of the thoughts and types of behaviour of these subjects was particularly bizarre but does not indicate that they had a psychotic disorder.

\section{A diagnosis of OCD}

A key feature in these cases that suggests obsessive-compulsive rather than psychotic psychopathology is the clear logical link between the thoughts and the rituals. The rituals are all cued by intrusive thoughts concerning a central belief, the patient feels compelled to carry them out to relieve associated distress, and they are all carried out 'ritualistically'. The patients are severely disabled by the illness but are otherwise intact. In particular, none of the subjects had other forms of thought disorder. Case $1 \mathrm{had}$ transient perceptual abnormalities, but these were clearly related to his obsessional phenomena. No other subject had other psychotic symptoms.

\section{Response to treatment}

Most of the patients had several medications. None had improved significantly with antipsychotic drugs, although several had improved somewhat on antidepressant selective serotonin reuptake inhibitors (SSRIs) or noradrenergic medication. Case 1 improved markedly with exposure and ritual prevention after a stormy and protracted course, with a temporary reemergence of severe depression. As his rituals reduced, so his belief in the 'power' weakened; he began to doubt its existence, and his perceptual abnormalities disappeared. His OCD symptoms improved independently of his mood. Case 2 had had adequate antipsychotic drugs, including clozapine, none of which had helped. With SSRIs he improved moderately in mood, but only to a limited extent in his OCD. He did not respond to a cognitivebehavioural intervention. Case 3 had failed to respond to several antipsychotics. Her mood improved with electroconvulsive therapy and SSRIs, but this did not help her other symptoms. She refused to "risk" ritual prevention. Case 4 was twice admitted to hospital for exposure and ritual prevention. He improved $70 \%$ the first time, but relapsed two months after discharge (his belief regarding external beings had not developed by then). During his second admission (eight years later) he did not improve or change his belief. Case 5 had three admissions for behaviour therapy. $\mathrm{He}$ did not improve during his first admission; but during the second and third (a further five years later) improved $25-30 \%$ and his beliefs weakened. He could not tolerate clomipramine and had not had an antipsychotic.

\section{Diagnostic issues}

The five patients described above form a rare group who had features consistent with OCD and also had delusions related to their rituals. Their features resemble those of an OCD sub-group noted by
Solyom et al (1985), characterised by an earlier onset age, more severe illness, and poorer prognosis. Other writers (Fear \& Healy, 1995) also described a sub-group of OCD subjects who had unusual, fixed beliefs, more affective symptoms and a singular theme to their obsessions. Fear \& Healy thought that these subjects had both obsessive and delusional features in the way that DSM-IV allows a "dual" diagnosis. Insel \& Akiskal (1986) argue against a dual diagnosis in such cases, saying that psychotic-type symptoms may emerge at the more severe end of the OCD spectrum, and regard such patients as having OCD "with psychotic features".

The diagnostic issues posed by these patients are not unique to OCD. Anorexia nervosa subjects may believe with 'absolute certainty' that they are fat, despite evidence to the contrary. These beliefs, despite their fixity, are generally called "overvalued ideas" (McKenna, 1984), the distinction from delusions perhaps being that the content of the belief is not 'alien' beyond normal understanding, although some would argue that the disturbance is of "delusional proportions" (Bruch, 1962). Patients with body dysmorphic disorder also have a range of beliefs from 'obsessional' at one end of the spectrum to 'delusional' at the other end. These are classified as separate disorders in DSM-IV ('body dysmorphic disorder' and 'delusional disorder - somatic type') although this separation is controversial (Phillips et al, 1995). These cases highlight the artificial nature of current diagnostic boundaries, and the limitations of Kraepelinian dichotomy in understanding and treating these disorders.

\section{Implications for management}

How one labels the psychopathology in these OCD subjects is of more than mere academic interest. A diagnosis of schizophrenia or delusional disorder may lead to a lifetime of antipsychotic medication and a reluctance to consider other, more effective, interventions. These subjects usually respond poorly to antipsychotic medication but may improve with clomipramine or SSRIs. Despite a view that fixity of belief adversely influences outcome with behaviour therapy (Foa, 1979), the marked improvement of Case 1 with exposure and ritual prevention (Lelliott \& Marks, 1987) and to a lesser extent of Case 5 suggests that the OCD of such subjects can respond to behaviour therapy. Moreover, in these cases, 
and in those reported by Lelliott et al (1988), belief normalised as the obsessivecompulsive features responded to treatment.

\section{REFERENCES}

American Psychiatric Association (1994) Diagnostic and Statistical Manual of Mental Disorders (4th edn) (DSM-IV). Washington, DC: APA.

Bruch, H. (1962) Perceptual and conceptual disturbance in anorexia nervosa. Psychosomatic Medicine, 24, 187-194.

Eisen, J. \& Rasmussen, S. A. (1993) Obsessive compulsive disorder with psychotic features. Journal of Clinical Psychiatry, 54, 373-379.

Fear, C. \& Healy, D. (1995) Obsessive compulsive disorders and delusional disorders: notes on their history, nosology and interface. Journal of Serotonin Research, I (suppl. I), I-13.

Foa, E. B. (1979) Failures in treating obsessivecompulsive disorder. Behaviour Research and Therapy, 17 169-176.

Insel, T. R. \& Akiskal, H. S. (1986) Obsessivecompulsive disorder with psychotic features: A phenomenologic analysis. American Journal of Psychiatry 143, 1527-1533.

Lelliott, P. \& Marks, I. (1987) Management of obsessive-compulsive rituals associated with delusions, hallucinations and depression: A case report. Behavioural Psychotherapy, 15, 77-87.

\section{_ , Noshirvani, H. F., Basoglu, M., et al (1988)}

Obsessive-compulsive beliefs and treatment outcome. Psychological Medicine, 18, 697-702.

Lewis, A. (1935) Problems of obsessional illness. Proceedings of the Royal Society of Medicine, 29, 325-336.

Maj, M. (1998) Critique of the DSM-IV operational diagnostic criteria for schizophrenia. British Journal of Psychiatry, 172, 458-460.

McKenna, P. J. (1984) Disorders with overvalued ideas. British journal of Psychiatry, 145, 579-585.

Phillips, K. A., Kim, J. M. \& Hudson, J. I. (1995) Body image disturbance in body dysmorphic disorder and eating disorders - obsessions or delusions? Psychiatric Clinics of North America, 18, 317-334.

\section{CLINICAL IMPLICATIONS}

- Patients with obsessive-compulsive disorder (OCD) may present with fixed, bizarre 'delusional' beliefs and loss of insight.

- These patients are best considered within an OCD management plan. Behavioural and/or pharmacological strategies used in $\mathrm{OCD}$ are the most appropriate first line of treatment.

- Use of long-term antipsychotic medication is not routinely recommended as patients are unlikely to respond. If used, it should be as a therapeutic trial, and response should be carefully monitored.

\section{LIMITATIONS}

- Only a small number of cases is presented.

- The cases may represent referral bias to a tertiary referral unit.

- The recommendations for management are based on the clinical experience of a specific unit.

ANNE-MARIE O'DWYER, MRCPsych, ISAAC MARKS, FRCPsych, Institute of Psychiatry and Maudsley Hospital, London

Correspondence: Professor I. M. Marks, Maudsley Hospital, De Crespigny Park, Denmark Hill, London SE5 8AZ

(First received I5 June 1999, final revision 24 September 1999, accepted 28 September 1999)

Rosen, I. (1957) The clinical significance of obsessions in schizophrenia. Journal of Mental Science, 103, 773-785.

\section{Solyom, L., Di Nicoal, V. F., Phil, M., et al (1985) is}

there an obsessive psychosis? Aetiological and prognostic factors of an atypical form of obsessive- compulsive neurosis. Canadian Journal of Psychiatry, 30 372-379.

World Health Organization (1992) International Classification of Diseases and Related Health Problems, Tenth Revision (ICD-10). Geneva: WHO 